Atmos. Chem. Phys., 18, 14433-14443, 2018

https://doi.org/10.5194/acp-18-14433-2018

(C) Author(s) 2018. This work is distributed under

the Creative Commons Attribution 4.0 License.

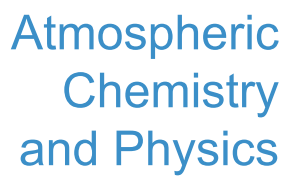

(c) (P)

\title{
Assessment of the pollution-health-economics nexus in China
}

\author{
Yang Xia ${ }^{1}$, Dabo Guan ${ }^{1}$, Jing Meng ${ }^{2}$, Yuan $\mathrm{Li}^{1}$, and Yuli Shan ${ }^{1}$ \\ ${ }^{1}$ Water Security Research Centre, School of International Development, University of East Anglia, Norwich NR4 7TJ, UK \\ ${ }^{2}$ Department of Politics and International Studies, University of Cambridge, Cambridge CB3 9DT, UK
}

Correspondence: Jing Meng (jm2218@cam.ac.uk) and Yuan Li (y.li4@uea.ac.uk)

Received: 14 May 2018 - Discussion started: 6 June 2018

Revised: 11 August 2018 - Accepted: 11 September 2018 - Published: 9 October 2018

\begin{abstract}
Serious haze can cause contaminant diseases that trigger productive labour time by raising mortality and morbidity rates in cardiovascular and respiratory diseases. Health studies rarely consider macroeconomic impacts of industrial interlinkages while disaster studies seldom involve air pollution and its health consequences. This study adopts a supplydriven input-output model to estimate the economic loss resulted from disease-induced working-time reduction across 30 Chinese provinces in 2012 using the most updated Chinese multiregional input-output table. Results show a total economic loss of CNY 398.23 billion ( $\sim 1 \%$ of China's GDP in 2012), with the majority coming from Eastern China and the Mid-South. The total number of affected labourers amounts to 82.19 million. Cross-regional economic impact analysis indicates that the Mid-South, North China, and Eastern China entail the majority of the regional indirect loss. Indeed, most indirect loss in North China, the Northwest and the Southwest can be attributed to manufacturing and energy in other regions, while loss in Eastern China, the Mid-South and the Northeast largely originate from coal and mining in other regions. At the subindustrial level, most inner-regional loss in North China and the Northwest originate from coal and mining, in Eastern China and Southwest from equipment and energy, and in the Mid-South from metal and non-metal. These findings highlight the potential role of geographical distance in regional interlinkages and regional heterogeneity in inner- and outer-regional loss due to distinctive regional economic structures and dependences between the north and south.
\end{abstract}

\section{Introduction}

Millions of people in China are currently breathing a toxic cocktail of chemicals, which has become one of the most serious environmental issues in China resulting in widespread environmental and health problems (Meng et al., 2015, 2016a), including increasing risks for heart and respiratory diseases, stroke, and lung cancer. As air pollution has longterm health impacts that evolve gradually over time, understanding the health and socioeconomic impacts of China's air pollution requires continuous efforts.

Serious air pollution in China has largely inspired epidemic studies that examine specific health outcomes from air pollution as well as health cost assessments that translate health outcomes into monetary loss (Xu et al., 2000; Venners et al., 2003; Kan and Chen, 2004). Existing epidemic studies simulate an exposure-response relationship between particulate matter (PM) concentration levels and relative risks (RRs) for a particular disease (see Wong et al., 1999, 2002; $\mathrm{Xu}$ et al., 2000; Venners et al., 2003), while health cost assessments frequently stem from patients' perspectives at microeconomic level, by evaluating either their willingnessto-pay (WTP) to avoid disease risk (see Wang and Mullahy, 2006; Wang et al., 2006; Zeng and Jiang, 2010) or the potentially productive years of life loss (PPYLL) (see Wan et al., 2005; Miraglia et al., 2005; Mcghee et al., 2006; Bradley et al., 2007). However, when perceiving unhealthy labourers as a degradation in labour input, macroeconomic implications for production supply chains lack investigation. While traditional approaches for health cost estimates are able to provide more information on economic loss from a standpoint of individual patients, we suggest that they are likely to lose sight on the cascading effects due to labour time loss across interrelating industries. Meanwhile, as the health ef- 
fects of air pollution are slowly built up over time, implying the lasting nature of air pollution, it has been rarely studied in current disaster risk literature. Differing from rapid-onset disaster analyses (flood, hurricane, earthquake, etc.) that normally rely on quantifying damages to physical capital, air pollution affects human capital more than physical capital, and the resulting health impacts are relatively invisible and unmeasurable. As a result, linking PM concentrations with health endpoints and further with macroeconomic impacts requires an interdisciplinary approach that integrates all three of the elements into one. Inspired by our previous work on the socioeconomic impacts of China's air pollution in 2007 (Xia et al., 2016), this paper applies a similar approach to China's air pollution in 2012 and also examines the crossregional economic impacts in order to underline the important role of indirect economic loss for the year 2012. In other words, it aims to investigate the overall economic loss resulting from health-induced labour time reduction among all Chinese labourers for year of 2012. Given that the majority of economic loss originates from secondary industries, this paper also specifically analyses the key sectors in secondary industries that account for the greatest proportions of both direct and indirect economic loss in each great region in China. By doing so, future policymakers and researchers could obtain an alternative macroeconomic tool to better conduct cost-benefit analysis for any environmental or climate change related policy design, and to comprehend health cost studies in its macroeconomic side.

\section{Methods}

\subsection{Methodological framework}

Figure 1 illustrates the overall methodological framework developed by this study. It involves four main parts that are distinguished by four colours. Detailed methods that connect each part in the flow chart are shown near the arrows.

$\mathrm{PM}_{2.5}$ concentration levels for 30 provinces of China were first identified from an emission inventory using an air quality simulation model. The relative risks for $\mathrm{PM}_{2.5}$-induced mortality (ischemic heart disease (IHD), stroke, chronic obstructive pulmonary disease (COPD), and LC), hospital admissions (cardiovascular and respiratory diseases), and outpatient visits (all causes) were estimated using an integrated exposure-response (IER) model based on which population attributable fraction (PAF) can be calculated to estimate counts of $\mathrm{PM}_{2.5}$-induced deaths, admissions, and outpatient visits. Additionally, counts of mortality, hospital admissions, and outpatient visits were further translated into a productive working time loss that was compared with the original industrial working time without any $\mathrm{PM}_{2.5}$-induced health effects (full employment and full productivity) to derive the percentage reduction in industrial value added. Moreover, reductions in industrial value added served as an input in the supply-driven input-output (IO) model to measure the total indirect economic loss incurred along the production supply chain, which is measured as the total loss in output level. Finally, macroeconomic implications regarding industrial and provincial economic loss can be obtained from our model results while cross-regional economic impacts can be investigated through multiregional economic analyses.

The following sections present many mathematical symbols, formulas, and equations. For clarity, matrices are indicated by bold, upright capital letters (e.g. X); vectors by bold, italicised lower case letters (e.g. $\boldsymbol{x}$ ); and scalars by italicised lower case letters (e.g. $x$ ). Vectors are columns by definition, so row vectors are obtained by transposition and are indicated by a prime (e.g. $\boldsymbol{x}^{\prime}$ ). A diagonal matrix with the elements of vector $\boldsymbol{x}$ on its main diagonal and all other entries equal to zero are indicated by a circumflex (e.g. $\hat{x}$ ).

\subsection{Provincial $\mathrm{PM}_{2.5}$ concentration levels}

We referred to Chinese provincial $\mathrm{PM}_{2.5}$ concentration levels estimated by Geng et al. (2015), where the authors improved the method for estimating long-term surface $\mathrm{PM}_{2.5}$ concentrations by using satellite remote sensing and a chemical transport model to assess the provincial $\mathrm{PM}_{2.5}$ concentration levels in China during 2006-2012. The model domain includes a map of surface $\mathrm{PM}_{2.5}$ concentrations at a resolution of $0.1^{\circ} \times 0.1^{\circ}$ over China using the nested-grid GEOSChem model with the most updated bottom-up emission inventory and satellite observations from the Moderate Resolution Imaging Spectroradiometer (MODIS) and Multi-angle Imaging SpectroRadiometer (MISR) instruments (Geng et al., 2015).

\subsection{Health impacts from $\mathbf{P M}_{2.5}$ concentration levels}

Epidemic studies on $\mathrm{PM}_{2.5}$-induced health outcomes have linked $\mathrm{PM}_{2.5}$ air pollution with various health endpoints by using exposure-response coefficients. This paper focuses on the impacts of $\mathrm{PM}_{2.5}$ pollution on mortality, hospital admissions, and outpatient visits. We referred to an integrated exposure-response model developed by Burnett et al. (2014) to estimate the relative risks for $\mathrm{PM}_{2.5}$-induced mortality (IHD, stroke, COPD, LC), hospital admissions (cardiovascular and respiratory diseases), and outpatient visits (all causes).

An IER model captures concentration-response relationships with a specific focus on ischemic heart disease, stroke, chronic obstructive pulmonary disease, and lung cancer. The relative risk for the mortality estimation function for the four diseases were shown in Eq. (1).

$\begin{array}{ll}\text { For } z<z_{\mathrm{cf}} & \operatorname{RR}_{\mathrm{IER}}(z)=1 \\ \text { For } z \geq z_{\mathrm{cf}} & \operatorname{RR}_{\mathrm{IER}}(z)=1+\alpha\left\{1-\exp \left[-\gamma\left(z-z_{\mathrm{cf}}\right)^{\delta}\right]\right\}\end{array}$

$z: \mathrm{PM}_{2.5}$ exposure in micrograms per metre cubed; $z_{\mathrm{cf}}$ : counter-factual concentration level below which no addi- 


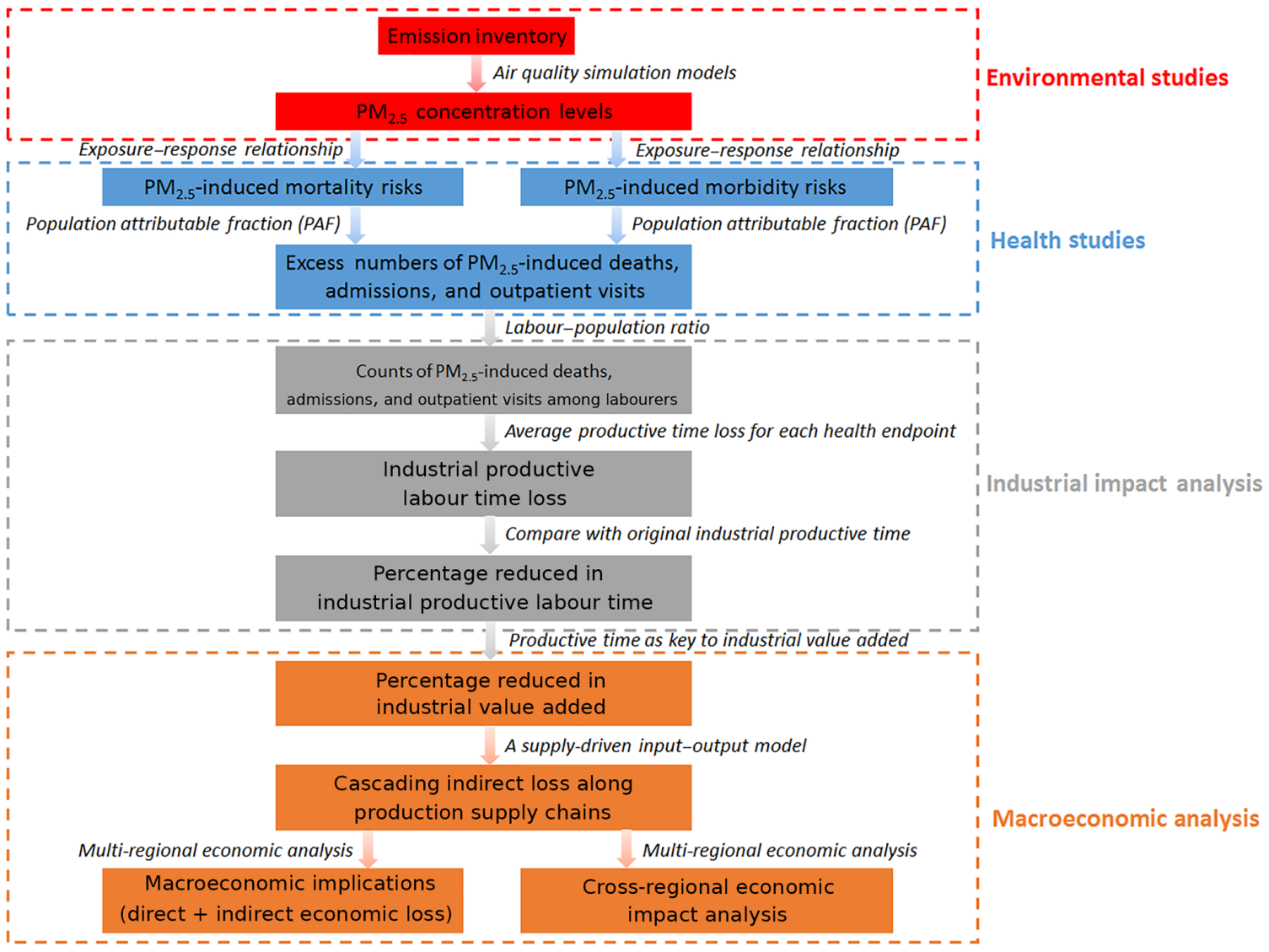

Figure 1. Methodological framework.

tional health risk is assumed; $\delta$ : the strength of $\mathrm{PM}_{2.5}$; and $\gamma$ : the ratio of RR at low-to-high exposures

Then, the calculated RR was converted into an attributable fraction (AF) in Eq. (2).

$\mathrm{AF}=\frac{\mathrm{RR}-1}{\mathrm{RR}}$

Additionally, excess counts of $\mathrm{PM}_{2.5}$ disease-induced mortality were estimated in Eq. (3).

$E=\mathrm{AF} \times B \times P$

$E: \mathrm{PM}_{2.5}$-induced mortality counts, $B$ : the national level incidence of a given health effect, which was applied for all provinces because of limited data; $P$ : the size of the exposed populations.

For morbidity, we calculated cardiovascular and respiratory hospital admissions and outpatient visits for all causes using a log-linear response function. The RRs for each category of morbidity were calculated using Eq. (4) (Jiang et al., 2015).

$\mathrm{RR}=e^{\beta x}$

$\beta$ : the parameter that describes the depth of the curve (Table S1 in the Supplement). They are the exposure-response coefficients to quantify the relationship between different levels of $\mathrm{PM}_{2.5}$ exposures and the resulting health outcomes.

Counts of $\mathrm{PM}_{2.5}$-induced hospital admissions, and outpatient visits were analogously estimated using Eqs. (2) and (3).

\subsection{Industrial labour time loss}

Each labourer is assumed to work $8 \mathrm{~h}$ every day and 250 days during 2012. For $\mathrm{PM}_{2.5}$-induced mortality, each death will result in a total 250 working days lost regardless different disease types. For $\mathrm{PM}_{2.5}$-induced morbidity, each cardiovascular admission will result in 11.9 working days lost while each respiratory admission causes 8.4 working days lost (Xia et al., 2016). Meanwhile, we provided a range for the labour time loss estimation of outpatient visits due to data unavailability, which ranges from 2 to $4 \mathrm{~h}$ per outpatient visit (Xia et al., 2018). We assumed each outpatient visits the clinic once during the year. Then, provincial mortality, hospital admissions, and outpatient visit counts were scaled down to counts among labourers according to labour-population ratios across all 30 of the provinces (National Statistical Yearbook, 2013). We further distributed provincial mortality, admissions, and outpatient counts into 30 industries accord- 
ing to an industrial-total provincial labour ratio. We used industrial-total provincial output ratio instead where certain industries' labour data is missing. Additionally, labour time loss for each case of mortality, admission, and outpatient visit were multiplied by industrial counts of mortality, admission, and outpatient visit in each province, respectively, and the results were summed up to derive the industrial total labour time loss due to $\mathrm{PM}_{2.5}$-induced mortality and morbidity. Moreover, we compared the industrial total labour time loss to the original labour time with full employment and labour productivity under no $\mathrm{PM}_{2.5}$-induced health impacts. The results show the percentage reductions in industrial working time, which were used as an indicator for percentage reductions in industrial value added in a supply-driven IO model, as we considered labour as the major component for industrial value added. We need to clarify that the industries can express very different levels of dependencies on capital and labour in reality. However, percentage reductions in labour time were used as a direct indicator for percentage reduction in industrial value added due to the assumption of the production expansion path underlying the input-output model. An input-output model assumes that proportional increase in industrial output can only be achieved by simultaneous increases in both capital and labour, indicating that any reduction in an input can directly constrain the output growth in all industries.

\subsection{Indirect economic loss on production supply chain}

We employed a supply-driven IO model to evaluate the indirect economic loss due to $\mathrm{PM}_{2.5}$-induced mortality and morbidity along production supply chain. A supply-driven IO model was developed based on a traditional Leontief IO model with the spirit of a "circular economy". A supplydriven IO model was derived from a traditional Leontief IO model. Input-output analyses have been widely applied to studies on energy usage (Guan et al., 2014), environmental pollution (Meng et al., 2015, 2016b), climate change mitigation and adaptation (Feng et al., 2013; Wiedmann et al., 2006), and economic perturbations (Steenge and Bočkarjova, 2007; Cho et al., 2001; Santos and Haimes, 2004; Crowther and Haimes, 2005) as well as to different scales, ranging from national to regional level. For a basic Leontief IO model, the total output of sector $i$ in an $n$-sector economy can be illustrated in Eqs. (5) and (6).

$x_{i}=z_{i 1}+\ldots .+z_{i j}+\ldots+z_{i n}+f_{i}=\sum_{j=1}^{n} Z_{i j}+f_{i}$

$\boldsymbol{x}=\mathbf{Z}+\boldsymbol{f}$

$x_{i}$ : the total output of sector $i ; \sum_{j=1}^{n} Z_{i j}$ : the monetary value of sector $i$ 's output in all other sectors; $f_{i}$ : sector $i$ 's final demand that includes household final consumption, government consumption, capital formation, and exports.
The basic Leontief IO model (Meng et al., 2018) can be therefore derived in matrix notation (Eq. 7a and 7b).

$\boldsymbol{x}=\mathbf{A} \boldsymbol{x}+\boldsymbol{f}$

$\boldsymbol{x}=(\mathbf{I}-\mathbf{A})^{-1} \boldsymbol{f}, \mathbf{L}=(\mathbf{I}-\mathbf{A})^{-1}$

A: matrix of technical coefficients, $a_{i j}$, where $a_{i j}=z_{i j} / x_{j}$; $\mathbf{L}$ : the Leontief inverse matrix that measures the impact of value change in the final demand of a sector on the total output value on the economy (Miller and Blair, 2009).

At the same time, a supply-driven IO model takes a rotated view of Leontief IO model that shows an opposite influencing direction between sectors. It suggests that production in a sector can affect sectors purchasing its outputs as inputs during their production processes and it has a supply-side focus. A supply-driven IO model is used to calculate the impact of changes in primary inputs on sectoral gross production. For a supply-driven IO model, the basic structure is shown in Eq. (8a) and (8b).

$\boldsymbol{x}^{\prime}=\boldsymbol{v}^{\prime}(\mathbf{I}-\mathbf{B})^{-1}$

$\boldsymbol{x}^{\prime}=\boldsymbol{v}^{\prime} \mathbf{G}, \mathbf{G}=(\mathbf{I}-\mathbf{B})^{-1}$

B: the allocation coefficient (direct output coefficient), where $b_{i j}=z_{i j} / x_{i}$. It refers to the distribution of sector $i$ 's outputs in sector $j ; \boldsymbol{v}$ : matrix of industrial value added, including capital and labour input; $\mathbf{G}$ : the Ghosh inverse matrix, which measures the economic impacts of changes in a sector's value added on other sectors' output level.

\section{Results}

\subsection{Total number of affected labour and total economic loss}

Firstly, regarding the total number of affected labourers and total economic loss, the total economic loss resulting from $\mathrm{PM}_{2.5}$-induced health outcomes in China 2012 is CNY 398.23 billion, which corresponds to almost $1 \%$ of national GDP in 2012. The total number of affected labourers in China is 0.80 million for $\mathrm{PM}_{2.5}$-induced mortality, 2.22 million for $\mathrm{PM}_{2.5}$-induced hospital admissions, and 79.17 million for $\mathrm{PM}_{2.5}$-induced outpatient visits (Fig. 2). Figure 2 presents the provincial counts of $\mathrm{PM}_{2.5}$-induced mortality, hospital admissions, outpatient visits, and economic loss with least severe and most severe situations shown from green to red. For total populations of $\mathrm{PM}_{2.5}$-induced mortality and morbidity among 30 provinces, Henan and Shangdong province have the largest total counts of $\mathrm{PM}_{2.5}$-induced mortality and morbidity, which is consistent with the findings in 2007 study (Xia et al., 2016). Guangdong province has the greatest counts of $\mathrm{PM}_{2.5}$-induced hospital admissions at 291 thousand, where a substantial increase of 175 thousand can be observed compared with results in 2007. It almost doubles its provincial count of outpatient visits and triples 


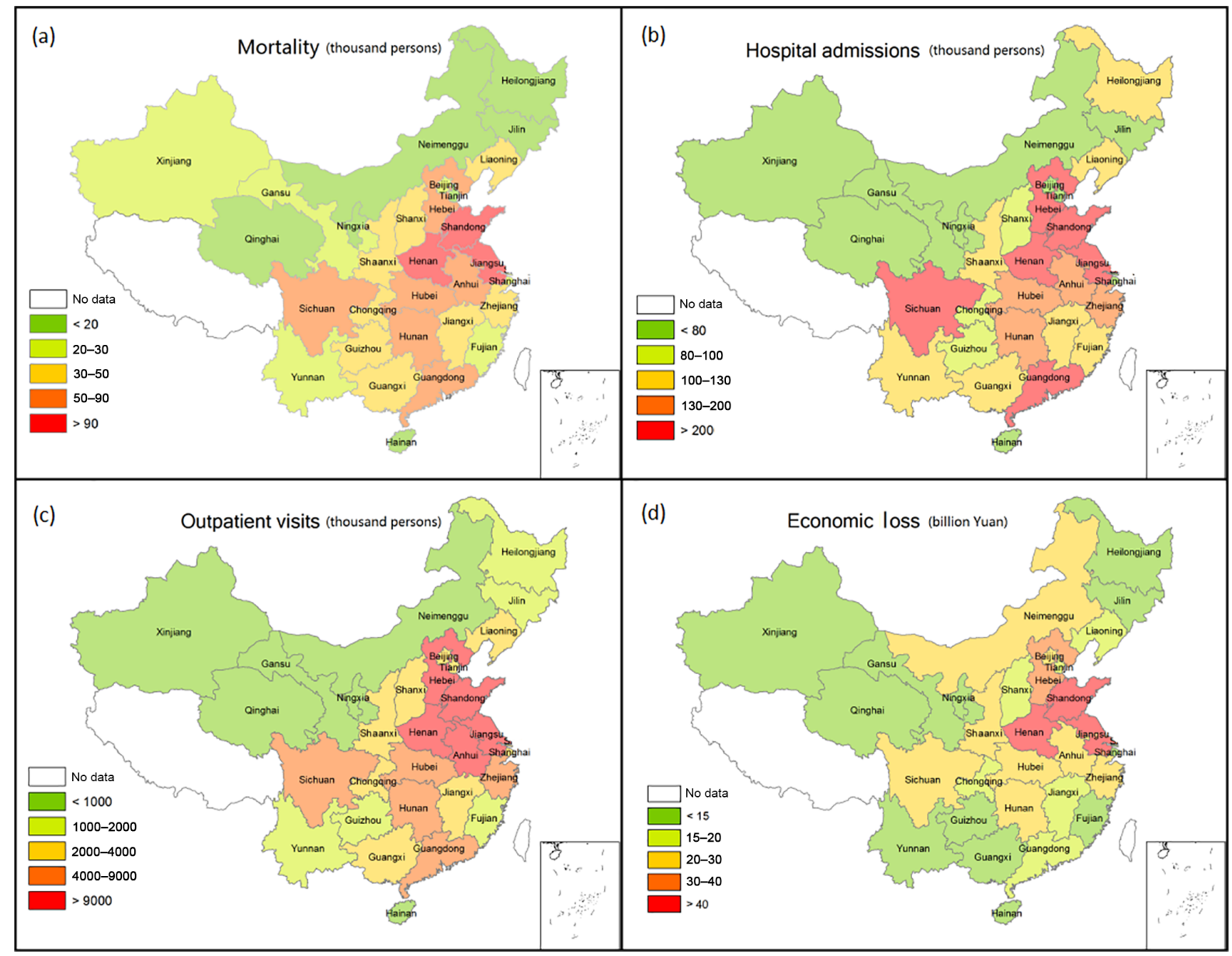

Figure 2. Provincial counts of $\mathrm{PM}_{2.5}$-induced mortality, hospital admissions, outpatient visits, and economic loss in the study area, 2012. Provincial counts of $\mathrm{PM}_{2.5}$-induced mortality (a), hospital admissions (b), outpatient visits (c), and economic loss (d) are displayed in the four panels above, with least severe and most severe situations shown from green to red. We did not consider Tibet due to the lack of data.

its mortality counts. Meanwhile, increases can be observed in both counts for the Northwest region, which includes Shaanxi, Gansu, Qinghai, Ningxia, and Xinjiang provinces. Specifically, the count of hospital admissions in the Shaanxi province in 2012, 100 thousand, also doubled that of the 50 thousand in 2007. An even sharper increase of admission counts can be seen in the Xinjiang province, where the number is almost 7 times that from 2007.

\subsection{Economic loss by provinces, regions, and industries}

Secondly, concerning economic loss by province, region, and industry at the provincial level (Fig. 2), the economic loss in the Henan province exceeds that of the Jiangsu province in 2007 (CNY 55.90 billion), becoming the province suffering the greatest economic loss at 56.37 billion, accounting for $14 \%$ of the total economic loss in China. This is followed by Jiangsu province at CNY 45.32 billion and Shangdong province at CNY 43.23 billion. This is because all three of the provinces have the largest counts of $\mathrm{PM}_{2.5}$-induced mortality and morbidity, which results in substantial provincial labour time loss. We also calculated the economic loss in China's six greater regions. Eastern China and the Mid-South appear to be the two regions suffering the greatest economic loss, amounting to CNY 153.39 and 119.21 billion, respectively, and accounting for $39 \%$ and $30 \%$ of total economic loss in China, 2012. It is in line with the findings from 2007 study (Xia et al., 2016), where the economic loss of these two regions are CNY 115.33 and 80.88 billion, respectively. Therefore, there has been a remarkable rise in economic loss for the Mid-South region. Primary industries, including agriculture and fishing, entailed the economic loss of CNY 19.12 billion. Secondary industries include all of the manufacturing, energy, and construction sectors, and they entail the greatest proportion of economic loss at CNY 320.06 billion $(80 \%$ of total economic loss). Tertiary industries (e.g. retail services and entertainment) account for the remaining $15 \%$ of total economic loss at CNY 59.05 billion. 


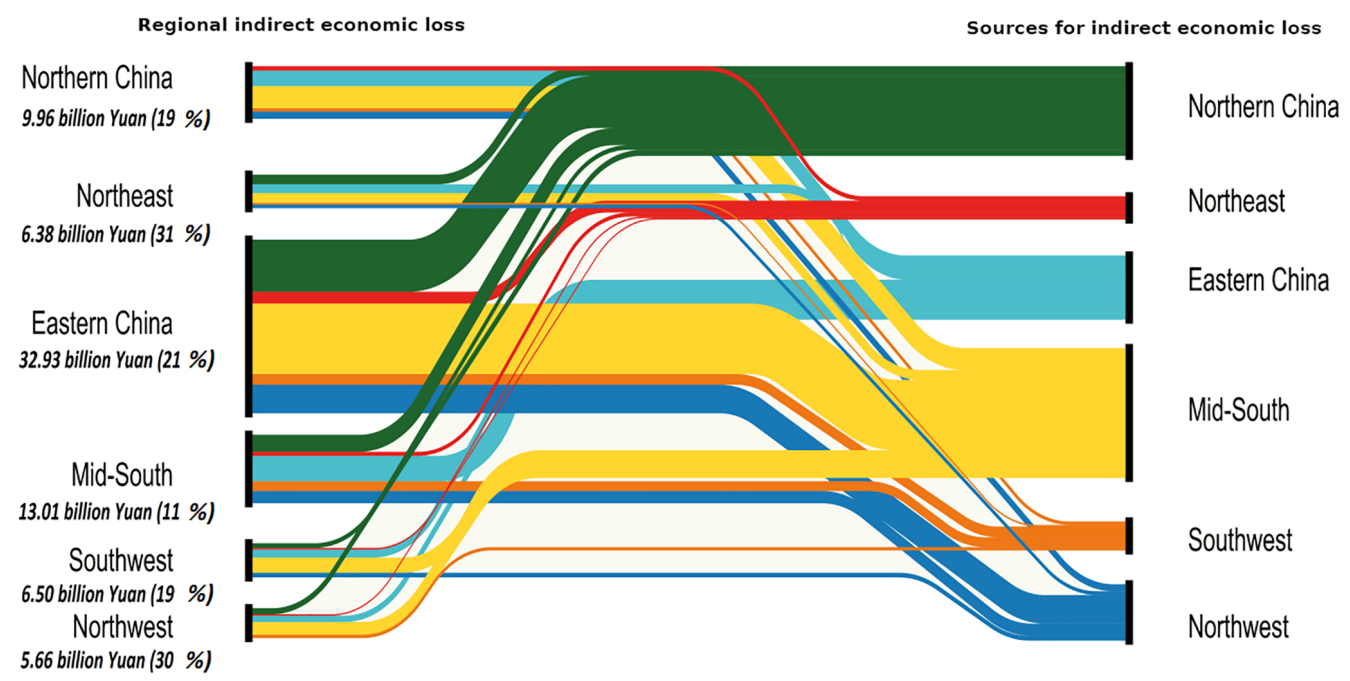

Figure 3. Cross-regional economic loss analysis. The diagram demonstrates the interregional economic impacts due to their interdependencies. The left-hand side shows the regional indirect economic loss while the right-hand side denotes the sources for these indirect economic losses. The proportion of regional indirect loss among regional total economic loss is displayed next to each region's name on the left-hand side.

\subsection{Cross-regional economic loss}

Additionally, this case study also examined the crossregional economic losses between the six greater regions in China. As one significant advantage of the input-output model is to capture the industrial and regional interdependencies, it is effective to measure the propagating disasterinduced indirect economic loss along the production supply chain. We traced the cross-regional economic loss due to their interlinkages, such as interregional trade, as shown in Fig. 3. The diagram demonstrates the interregional economic impacts due to their interdependencies. The proportion of regional indirect loss among regional total economic loss is displayed next to each region's name on the left-hand side. Although the majority of regional economic loss came from the direct economic loss that occurred within the region across almost all six of the regions, the Northeast, Eastern China, and the Northwest still entail great indirect economic loss from other regions, which occupies $31 \%, 21 \%$, and $30 \%$ of the total regional economic loss, respectively. In the Northeast, $18 \%$ of its total regional economic loss originated from North China and Mid-South, including CNY 1.84 billion from North China and CNY 1.85 billion from MidSouth. Similarly, the Mid-South is responsible for $9 \%$ of the economic loss in Eastern China at CNY 13.36 billion. It accounts for an even larger proportion of regional economic loss in the Northwest at $13 \%$. Meanwhile, Eastern China also accounts for another $8 \%$ of the total regional economic loss in Northeast, which amounts to CNY 1.66 billion. Overall, the Mid-South accounts for the largest amount of indirect economic loss in other Chinese regions at CNY 24.65 billion, which is followed by North China and Eastern China at CNY 16.99 and 12.17 billion, respectively. This finding highlights the increasing significance in capturing the industrial and regional interdependencies and indirect economic loss in disaster risk analysis because such interdependencies can largely raise the overall economic loss far beyond the direct economic loss and constitute a noticeable component of total economic loss.

\subsection{Regional direct and indirect loss from secondary sector}

As secondary sectors play a vital role in the Chinese economy and entails greatest economic loss among the three industries, we specifically analysed the regional economic loss that directly and indirectly resulting from secondary sectors both inside and outside of a region. Focusing on the secondary sector, Fig. 4 illustrates both direct and indirect economic loss originating from each region and outside the region. As can be seen from the diagram, despite the fact that the majority of economic loss resulting from the secondary sectors originated from inside the region for all six of the greater regions in China, in the Northwest and the Northeast, economic loss attributed to secondary sectors outside the region still constituted a considerable share due to industrial and regional interdependencies. Secondary sectors in the Mid-South, Eastern China, and North China became three major sources for indirect economic loss across all six of the regions. For instance, in the Northwest, economic loss from secondary sectors in the Mid-South, Eastern China, and North China account for $14 \%, 6 \%$, and $6 \%$ of total regional indirect loss from secondary sectors outside the region, at CNY 2.20, 0.99, and 0.90 billion, respectively. Similarly, in the Northeast, economic loss from secondary sectors in these 


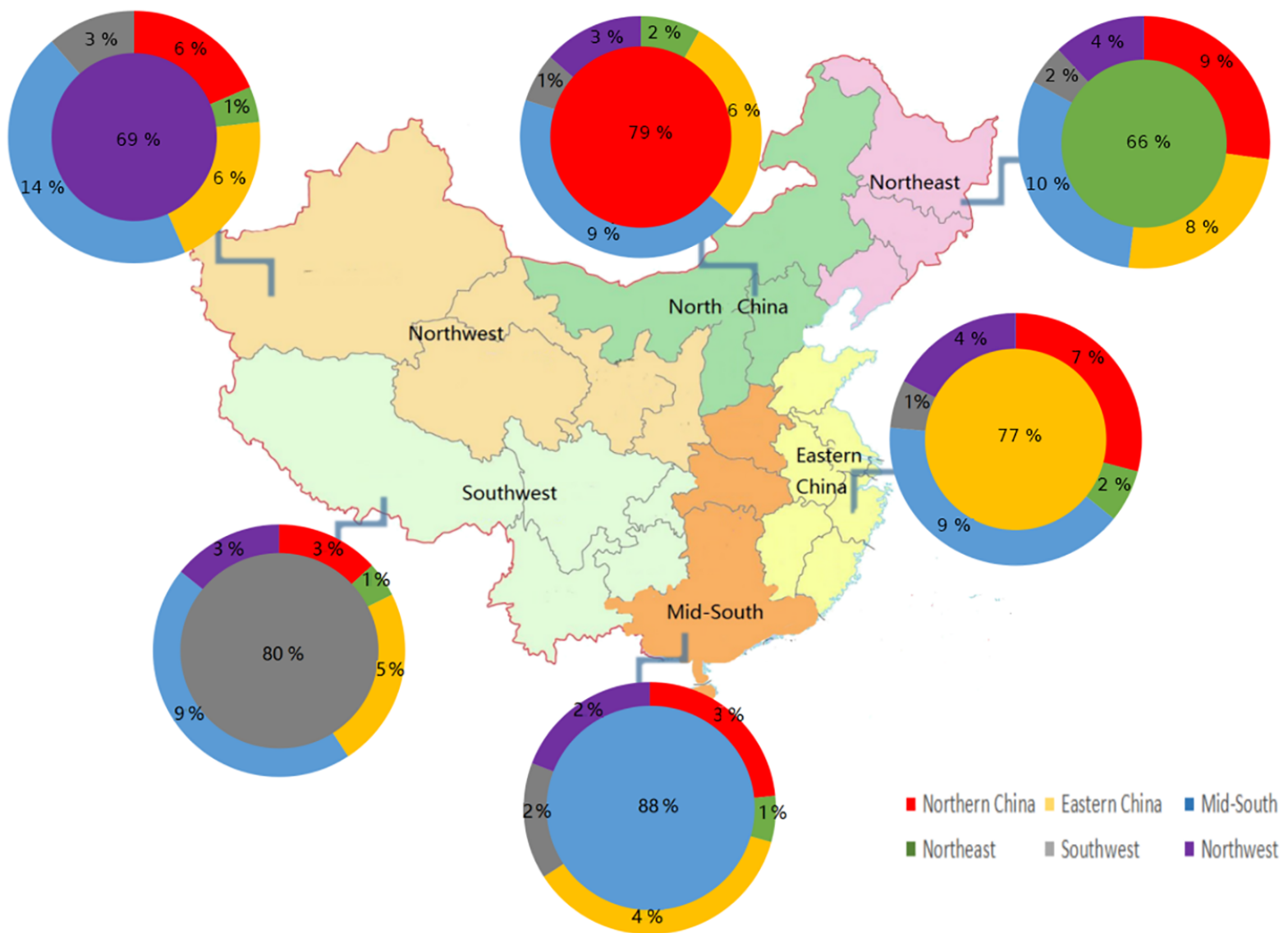

Figure 4. Regional direct and indirect economic loss from secondary sectors. The inner ring denotes the direct economic loss originating from secondary sectors inside the region, while the outer ring stands for the indirect economic loss from secondary sectors in other regions. Percentage shown on the inner ring shows the proportion of direct economic loss regarding total regional economic loss and percentages shown on the outer ring are the proportions of indirect loss from other regions relative to total regional indirect economic loss.

three regions occupy $10 \%, 8 \%$, and $9 \%$ of total regional indirect loss from secondary sectors outside the region, at CNY 1.66, 1.33, and 1.46 billion, respectively. This results from their geographical distance to the Mid-South, Eastern China, and North China, as well as close trade relationships with these three regions. The significant roles of Mid-South and Eastern China in interregional trade have been confirmed earlier by Sun and Peng (2011), where they pointed out the export-oriented nature for trades in Eastern China and the Mid-South, and their close trade relations with Northwest regions with respect to the import of raw materials. Likewise, it is noticeable that indirect economic loss is more likely to come from neighbour-regions, which highlights the possibility that short geographical distances might accelerate interregional trade and strengthen regional interlinkages.

\subsection{Direct, indirect loss from subindustries in secondary sector}

The secondary sector was further broken down into seven industries in order to examine the major economic loss sources among subindustries inside and outside the region. They include coal and mining, manufacturing, fuel processing and chemicals, metal and non-metal, equipment, energy, and construction as displayed in Fig. 5. In North China, the Northwest and the Southwest, most of their indirect economic loss from secondary sectors outside the region came from manufacturing with $27.0 \%, 26.7 \%$, and $22.2 \%$, respectively. The second largest source in these three regions that accounts for economic loss from secondary sectors in other regions is energy, with the greatest amount occurring in North China at CNY 2.32 billion, followed by the Northwest at CNY 1.29 billion, and the Southwest at CNY 1.26 billion. In contrast, coal and mining accounts for the majority of indirect loss from secondary sectors outside the region for Eastern China, the Mid-South and the Northeast at $37.4 \%$ (CNY 10.83 billion), $33.4 \%$ (CNY 3.65 billion), and $24.4 \%$ (CNY 1.30 billion), respectively. One possible underlying reason is that economies in the Northwest, North China, and the Southwest are mainly dominated by coal and mining but rely on the import of manufacturing products from 


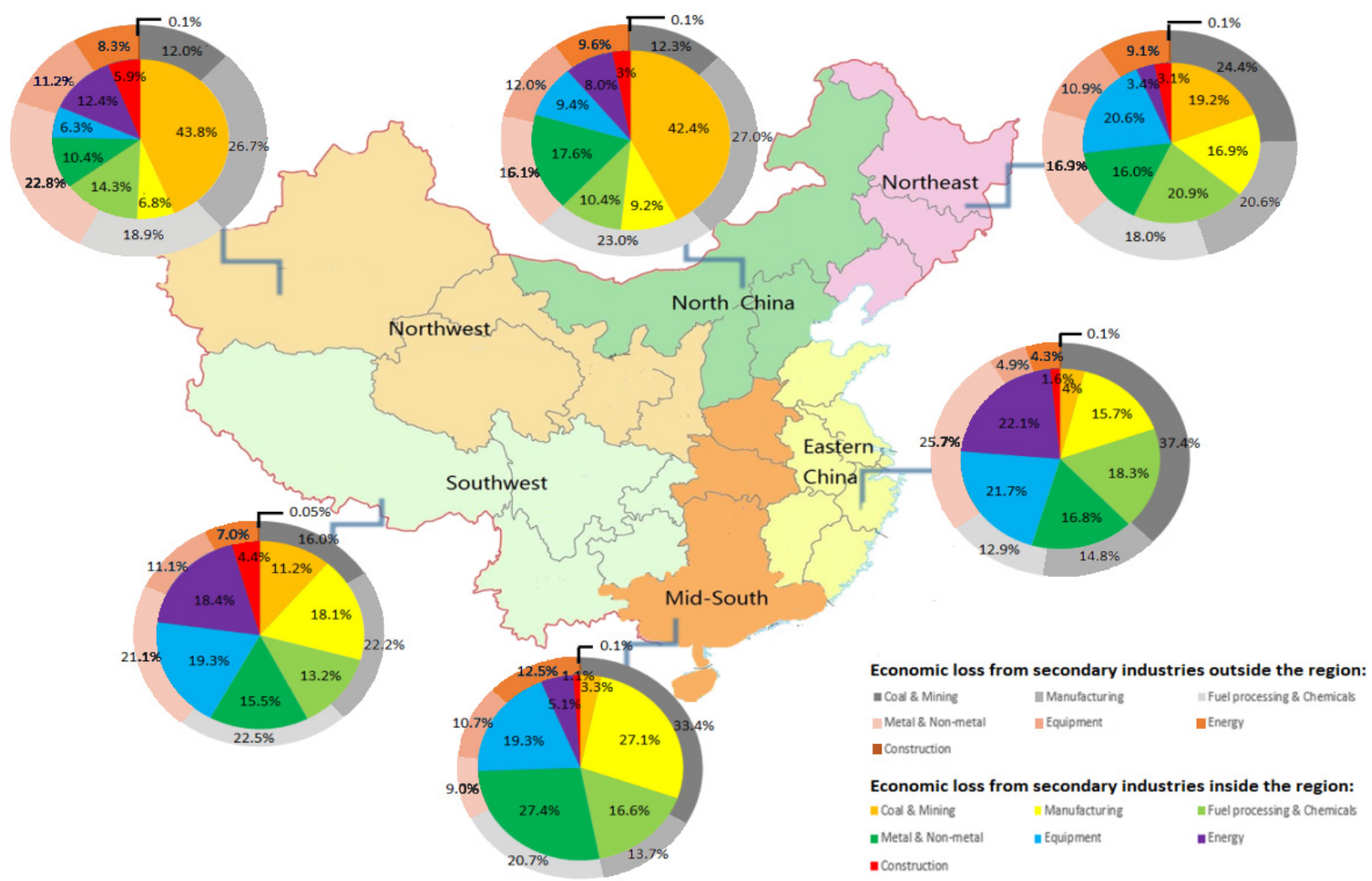

Figure 5. Economic loss from seven industries in secondary sector inside and outside the region. The inner circle shows the economic loss from secondary sector inside the region. The size of circle stands for the different proportions of inner-regional economic loss relative to total regional economic loss. Colours demonstrate economic loss from seven sectors in secondary sector inside the region. Meanwhile, the outer circle indicates the economic loss from secondary sectors outside the region. Economic loss resulting from seven sectors are shown in black and white. Percentages shown on the outer circle are the proportions of indirect loss from other regions relative to total regional indirect economic loss.

other regions, whereas Eastern China, the Mid-South, and the Northeast have more prosperous manufacturing industries but tend to heavily depend on imports of raw materials from coal and mining industries in the Northwest, North China, or the Southwest. With regards to the economic loss from secondary sectors inside each region, it shows diversified patterns across the six greater regions. Coal and mining account for the largest part of inner-regional economic loss in North China and the Northwest at $42.4 \%$ and $43.8 \%$, respectively. Equipment and energy appear to be two major sources for inner-regional economic loss Eastern China and the Southwest, while metal and non-metal and manufacturing constitute considerable proportions in inner-regional economic loss from secondary sectors in the Mid-South, which reach CNY 21.86 and 21.61 billion, occupying $27.4 \%$ and $27.1 \%$, respectively.

\section{Discussions}

$\mathrm{PM}_{2.5}$ has seriously undermined human health by inducing contaminant diseases, including IHD, Stroke, COPD and LC. These diseases have resulted in substantial numbers of mortality and morbidity that further cause labour degradation in terms of productive working time loss along production supply chain. Therefore, there is a growing need to explore the macroeconomic implications of $\mathrm{PM}_{2.5}$-induced health effects that can also capture industrial and regional interdependencies. However, existing health cost studies assess the health costs at the microeconomic level without an investigation over these linkages on the production supply side. Meanwhile, disaster risk studies rarely involve $\mathrm{PM}_{2.5}$ pollution as a disaster that harms human capital more than physical capital. Thus, methods to quantify the direct damages to infrastructure seem to be inefficacious when measuring the "damages" to human health. Inspired by the previous study on China's air pollution in 2007 (Xia et al., 2016), the current study applies an interdisciplinary approach to assess the macroeco- 
nomic impacts of $\mathrm{PM}_{2.5}$-induced health effects in China 2012 by perceiving reduced labour time as an indicator for reduced value added so that it can be fed back into a supply-driven IO model, and health studies can be integrated into impact evaluation and interdependency analysis. The current case study applies an interdisciplinary approach by combining environmental, epidemiological, and macroeconomic studies to assess the macroeconomic impacts of $\mathrm{PM}_{2.5}$-induced health effects in China during 2012. In the model, environmental phenomenon was related with health endpoints using an integrated exposure-response model, reduction in labour time was estimated based on the pollution-induced mortality and morbidity counts, and industrial reduced labour time was perceived as an indicator for industrial reduced value added, which was further fed back into a supply-driven input-output model. By doing so, health studies can be integrated into impact evaluation and interdependency analyses.

The results are threefold. Firstly, the total economic loss from China's air pollution during 2012 amounts to CNY 398.23 billion with the majority coming from Eastern China (39\%) and the Mid-South (30\%). The total economic loss is equivalent with $1.0 \%$ of China's GDP in 2012, and the total number of affected labourers rises to 82.19 million. Compared with the study in 2007 (Xia et al., 2016), although secondary industries remain as the industries which encountered the most economic loss $(80 \%)$, changes can be noticed for economic loss at the provincial level. Henan and Jiangsu became two provinces that suffered the greatest economic loss at CNY 56.37 and 45.32 billion, respectively, followed by Shangdong province with a total economic loss of CNY 43.23 billion. Henan and Shangdong provinces also have the largest numbers of $\mathrm{PM}_{2.5}$-induced mortality, hospital admissions, and outpatient visits. Secondly, the study highlights the cascading indirect economic loss triggered by industrial and regional interdependencies in health cost assessments. In 2012, indirect economic loss constituted a significant part of the total regional economic loss in the Northeast, Eastern China and the Northwest, which occupied $31 \%, 21 \%$ and $30 \%$ of the total regional economic loss, respectively. Overall, the Mid-South accounts for the largest amount of indirect economic loss in other Chinese regions at CNY 24.65 billion, which is followed by North China and Eastern China at CNY 16.99 and 12.17 billion, respectively. Additionally, the study specifically focuses on seven sectors in the secondary industries and differentiates economic loss from these sectors inside the region from those outside the region. In Northwest and Northeast, economic loss attributed to secondary industries outside the region still constitute a considerable share due to industrial and regional interdependencies at $31 \%$ and $34 \%$ of total regional economic loss, respectively. Secondary industries in the MidSouth, Eastern China, and North China became three major sources for indirect economic loss across all the six regions. Indeed, we also suggest that indirect economic loss is more likely to come from neighbour-regions, which highlights the possibility that short geographical distance might accelerate interregional trade and strengthen regional interlinkages. In North China, Northwest, and Southwest, most of their indirect economic losses originated from manufacturing industries outside the region with $27.0 \%, 26.7 \%$, and $22.2 \%$, respectively. The second largest source in these three regions that accounts for economic loss from secondary industries in other regions is energy, with the greatest amount occurring in North China at CNY 2.32 billion. In contrast, coal and mining accounts for the majority of indirect loss from secondary industries outside the region for Eastern China, the Mid-South, and the Northeast at $37.4 \%$ (CNY 10.83 billion), $33.4 \%$ (CNY 3.65 billion) and $24.4 \%$ (CNY 1.30 billion), respectively. Such distinctive compositions of outer-regional economic loss might be due to the different economic structures and dependences between North China, the Northwest, and the Southwest, and Eastern China, the Mid-South, the Northeast. Turning to the economic loss from secondary industries inside the region, regions show heterogeneity. Coal and mining account for the largest part of inner-regional economic loss in North China and the Northwest at $42.4 \%$ and $43.8 \%$, respectively, equipment and energy are two major sources for inner-regional economic loss Eastern China and the Southwest, while metal and non-metal and manufacturing constitute considerable proportions in inner-regional economic loss from secondary industries in the Mid-South.

There are some final remarks for policymakers and researchers here from this typical air pollution issue. On the one hand, given the prosperous interregional trade, policymakers are required to conscientiously consider these increasingly strengthened industrial and regional linkages in climate change mitigation and adaptation policy design based on a better understanding of implications resulting from any climate change-induced health issues at both micro and macroeconomic levels. Meanwhile, sufficient adaptation measures are required to be implemented along with the climate change mitigation strategies in operation. The purpose of this is to expand the economy beyond the regional geography and natural endowment and to release the current reliance on the economy on labour-intensive sectors (Mauricio Mesquita, 2007). On the other hand, researchers of epidemic studies should actively integrate these interdependencies into future health cost evaluations, while researchers of disaster risk analyses should not lose sight on "persistent" disasters as described in this study, which affect more human capital and may imply degradation in production factor inputs.

Data availability. The data that support the findings of this study are available from the corresponding author on request.
The Supplement related to this article is available online at https://doi.org/10.5194/acp-18-14433-2018- supplement. 
Author contributions. DG and YX designed the study and YX carried it out. JM constructed the multiregional input-output table for China, 2012. YL and YS provided the requested dataset. YX prepared the paper with contributions from all co-authors.

Competing interests. The authors declare that they have no conflict of interest.

Special issue statement. This article is part of the special issue "In-depth study of air pollution sources and processes within Beijing and its surrounding region (APHH-Beijing) (ACP/AMT interjournal SI)". It is not associated with a conference.

Acknowledgements. This work was supported by the National Key R\&D Program of China (2016YFA0602604), the National Natural Science Foundation of China (41629501, 71873059, and 71533005), the Chinese Academy of Engineering (2017ZD-15-07), the UK Natural Environment Research Council (NE/N00714X/1 and NE/P019900/1), and the Economic and Social Research Council (ES/L016028/1).

Edited by: Pingqing Fu

Reviewed by: two anonymous referees

\section{References}

Bradley, C. J., Neumark, D., Luo, Z., and Schenk, M.: Employment and cancer: findings from a longitudinal study of breast and prostate cancer survivors, Cancer Invest., 25, 47-54, 2007.

Burnett, R. T., Pope III, C. A., Ezzati, M., Olives, C., Lim, S. S., Mehta, S., Shin, H. H., Singh, G., Hubbell, B., Brauer, M., Anderson, H. R., Smith, K. R., Balmes, J. R., Bruce, N. G., Kan, H., Laden, F., Prüss-Ustün, A., Turner, M. C., Gapstur, S. M., Diver, W. R., and Cohen A.: An integrated risk function for estimating the global burden of disease attributable to ambient fine particulate matter exposure, Environ. Health Persp., 122, 397403, 2014.

Cho, S., Gordon, P., Moore II, J. E., Richardson, H. W., Shinozuka, M., and Chang, S.: Integrating transportation network and regional economic models to estimate the costs of a large urban earthquake, J. Regional Sci., 41, 39-65, 2001.

Crowther K. G. and Haimes Y. Y.: Application of the inoperability input-output model (IIM) for systemic risk assessment and management of interdependent infrastructures, Syst. Eng., 8, 323341, 2005.

Feng, K., Davis, S. J., Sun, L., Li, X., Guan, D., Liu, W., Liu, Z., and Hubacek, K.: Outsourcing $\mathrm{CO}_{2}$ within China, P. Natl. Acad. Sci. USA, 110, 11654-11659, 2013.

Geng, G., Zhang, Q., Martin, R. V., van Donkelaar, A., Huo, H., Che, H., Lin, J., and He, K.: Estimating long-term $\mathrm{PM}_{2.5}$ concentrations in China using satellite-based aerosol optical depth and a chemical transport model, Remote Sens. Environ., 166, 262-270, 2015.

Guan, D., Su, X., Zhang, Q., Peters, G. P., Liu, Z., Lei, Y., and He, K.: The socioeconomic drivers of China's pri- mary $\mathrm{PM}_{2.5}$ emissions, Environ. Res. Lett., 9, 024010, https://doi.org/10.1088/1748-9326/9/2/024010, 2014.

Jiang, X., Zhang, Q., Zhao, H., Geng, G., Peng, L., Guan, D., Kan, H., Huo, H., Lin, J., Brauer, M., Martin, R. V., and He, K.: Revealing the hidden health costs embodied in Chinese exports, Environ. Sci. Technol., 49, 4381-4388, 2015.

Kan, H. and Chen, B.: Particulate air pollution in urban areas of Shanghai, China: health-based economic assessment, Sci. Total Environ., 322, 71-79, 2004.

Mcghee, S. M., Ho, L. M., Lapsley, H. M., Chau, J., Cheung, W. L., Ho, S. Y., Pow, M., Lam, T. H., and Hedley, A. J.: Cost of tobacco-related diseases, including passive smoking in Hong Kong, Tob. Control, 15, 125-130, 2006.

Meng, J., Liu, J., Xu, Y., and Tao, S.: Tracing Primary $\mathrm{PM}_{2.5}$ emissions via Chinese Supply Chains, Environ. Res. Lett., 10, 054005, https://doi.org/10.1088/1748-9326/10/5/054005, 2015.

Meng, J., Liu, J., Fan, S., Kang, C., Yi, K., Cheng, Y., Shen, X., and Tao, S.: Potential health benefits of controlling dust emissions in Beijing, Environ. Pollut., 213, 850-859, 2016a.

Meng, J., Liu, J., Xu, Y., Guan, D., Liu, Z., Huang, Y., and Tao, S.: Globalization and pollution: tele-connecting local primary $\mathrm{PM}_{2.5}$ emissions to global consumption, P. R. Soc. A., 472, 20160380, https://doi.org/10.1098/rspa.2016.0380, 2016 b.

Meng, J., Mi, Z., Guan, D., Li, J., Tao, S., Li, Y., Feng, K., Liu, J., Liu, Z., Wang, X., Zhang, Q., and Davis, S. The rise of SouthSouth trade and its effect on global $\mathrm{CO}_{2}$ emissions, Nat. Commun., 9, https://doi.org/10.1038/s41467-018-04337-y, 2018.

Mesquita Moreira, M.: Fear of China: Is There a Future for Manufacturing in Latin America?, World Development, 35, 355-376, 2007.

Miller, R. E. and Blair, P. D.: Input-output analysis: foundations and extensions, Cambridge University Press, 2009.

Miraglia, S. G. E. K., Saldiva, P. H. N., and Böhm, G. M.: An evaluation of air pollution health impacts and costs in São Paulo, Brazil, Environ. Manage., 35, 667-676, 2005.

National Statistical Yearbook 2013: available at: http://www.stats. gov.cn/tjsj/ndsj/2013/indexch.htm/, last access: 31 January 2017.

Santos, J. R. and Haimes, Y. Y.: Modeling the Demand Reduction Input-Output (I-O) Inoperability Due to Terrorism of Interconnected Infrastructures, Risk Anal., 24, 1437-1451, 2004.

Steenge, A. E. and Bočkarjova, M.: Thinking about imbalances in post-catastrophe economies: an input-output based proposition, Econ. Syst. Res., 19, 205-223, 2007.

Sun, J. and Peng, W.: Domestic Interregional trade based on regional trade relations, Soc. Sci. Res., 6, 20-25, 2011 (in Chinese).

Venners, S. A., Wang, B., Xu, Z., Schlatter, Y., Wang, L., and $\mathrm{Xu}, \mathrm{X}$.: Particulate matter, sulfur dioxide, and daily mortality in Chongqing, China, Environ. Health Persp., 111, 562-567, 2003.

Wan, Y., Yang, H., and Masui, T.: Air pollution-induced health impacts on the national economy of China: demonstration of a computable general equilibrium approach, Rev. Environ. Health, 20, 119-140, 2005.

Wang, H. and Mullahy, J.: Willingness to pay for reducing fatal risk by improving air quality: a contingent valuation study in Chongqing, China, Sci. Total Environ., 367, 50-57, 2006.

Wang, X. J., Zhang, W., Li, Y., Yang, K. Z., and Bai, M.: Air quality improvement estimation and assessment using contingent valua- 
tion method, a case study in Beijing, Environ. Monit. Assess., 120, 153-168, 2006.

Wong, C. M., Atkinson, R. W., Anderson, H. R., Hedley, A. J., Ma, S., Chau, P. Y. K., and Lam, T. H.: A tale of two cities: effects of air pollution on hospital admissions in Hong Kong and London compared, Environ. Health Persp., 110, 67-77, 2002.

Wong, T. W., Lau, T. S., Yu, T. S., Neller, A., Wong, S. L., Tam, W., and Pang, S. W.: Air pollution and hospital admissions for respiratory and cardiovascular diseases in Hong Kong, Occup. Environ. Med., 56, 679-683, 1999.

Wiedmann, T., Minx, J., Barrett, J., and Wackernagel, M.: Allocating ecological footprints to final consumption categories with input-output analysis, Ecol. Econ., 56, 28-48, 2006.
Xia, Y., Guan, D., Jiang, X., Peng, L., Schroeder, H., and Zhang, Q.: Assessment of socioeconomic costs to China's air pollution, Atmos. Environ., 139, 147-156, 2016.

Xia, Y., Li, Y., Guan, D., Tinoco, D. M., Xia, J., Yan, Z., Yang, J., Liu, Q., and Huo, H.: Assessment of the economic impacts of heat waves: A case study of Nanjing, China, J. Clean. Prod., 171, 811-819, 2018.

$\mathrm{Xu}, \mathrm{Z}$., Yu, D., Jing, L., and Xu, X.: Air pollution and daily mortality in Shenyang, China, Arch. Environ. Health, 55, 115-120, 2000.

Zeng, X. and Jiang, Y.: Evaluation of value of statistical life in health costs attributable to air pollution, China Environmental Science, 30, 284-288, 2010. 